involve the ulnar ligament (Lamb, Abernethy and Fragiadakis 1971). Probably, the axial compressive forces responsible for the basal fractures are more likely to stress the radial than the ulnar collateral ligament.

The actual frequency of the combined lesion cannot be estimated from our material. Ligamentous lesions on the radial side and proximal ulnar lesions may heal with full stability. We found no cases of late symptomatic instability at follow-up of 50 patients with either Bennett or Rolando fractures (Kjaer-Petersen, Langhoff and Andersen 1990; Langhoff, Andersen and Kjaer-Petersen 1990), but some of these may have had ruptures through the ligamentous substance, which normally outnumber bony avulsions by almost four to one (Smith 1977).

Both components of this combined lesion may need surgical treatment, especially intra-articular fractures and ulnar collateral ligament lesions. Primary surgical treatment is more rewarding than secondary reconstruction, so that primary diagnosis of both lesions is important. We recommend that when one of these lesions is diagnosed, the other should be sought.

No benefits in any form have been received or will be received from a commercial party related directly or indirectly to the subject of this article.

\section{REFERENCES}

Lamb DW, Abernethy PJ, Fragiadakis E. Injuries of the metacarpophalangeal joint of the thumb. Hand 1971; 3:164-8.

Kjaer-Petersen $\mathbf{K}$, Langhoff $\mathbf{O}$, Andersen $\mathbf{K}$. Bennett's fracture. $J$ Hand Surg [Br] 1990; 15-B:58-61.

Langhoff O, Andersen K, Kjaer-Petersen K. Rolando's fracture. J Hand Surg [ $\mathrm{Br}] 1990$; in press.

Smith RJ. Post-traumatic instability of the metacarpophalangeal joint of the thumb. J Bone Joint Surg [Am] 1977; 59-A :14-21.

\title{
WHEELGUARDS: A SAFETY MEASURE IN THE OPERATING ROOM
}
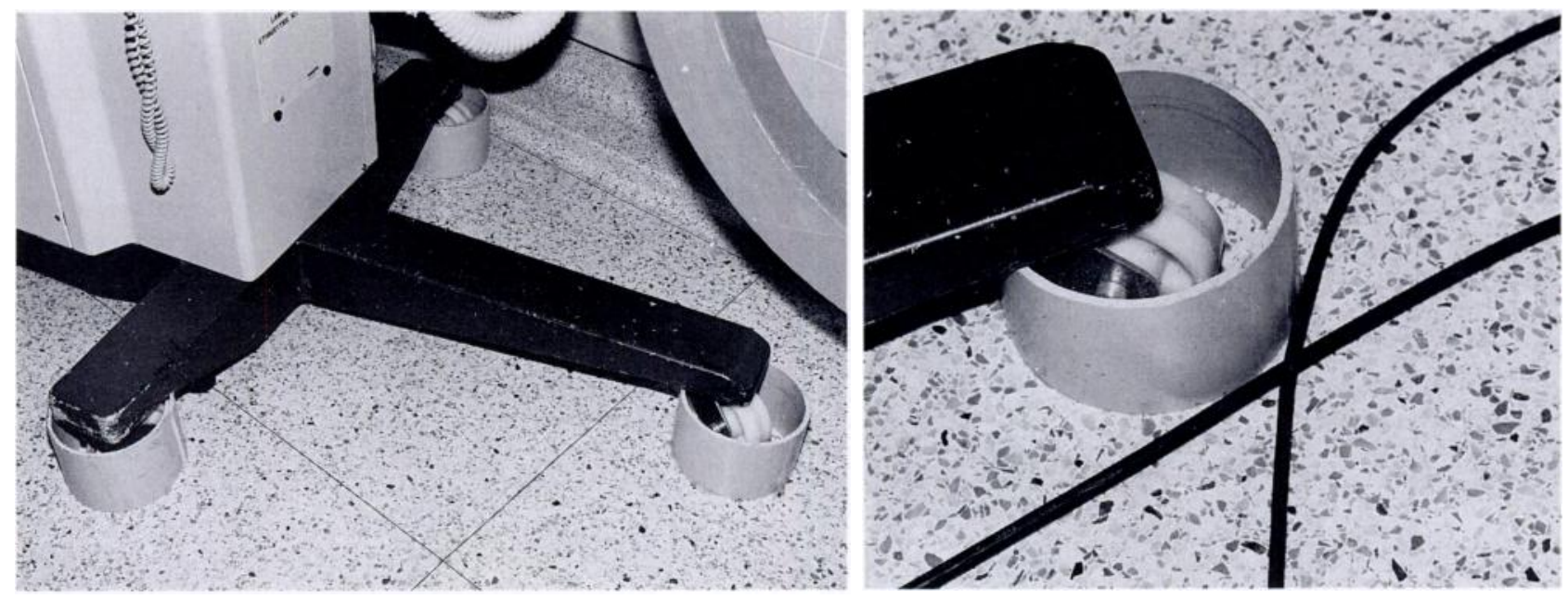

In the operating room there are X-ray machines, anaesthesia machines and other things on wheels. There are also many pipes and cables which may jam the wheels.

M. Rang, FRCS C, Professor

University of Toronto, Hospital for Sick Children, 555 University Avenue, Ontario, Canada M5Q 1 X8.

(C) 1991 British Editorial Society of Bone and Joint Surgery 0301-620X/91/1 R94 \$2.00

J Bone Joint Surg [ Br] 1991 ; 73-B:177.
This problem can be overcome if a short length of plastic drainpipe is placed around each wheel. The wheelguard pushes the cable away and the machine can be moved freely over the operating room floor. A slit cut in the drainpipe enables the wheelguard to be removed if necessary.

No problems have been encountered in a year of use.

No benefits in any form have been received or will be received from a commercial party related directly or indirectly to the subject of this article. 